\title{
The Caucasian Clover Gene TaMYC2 Responds to Abiotic Stress and Improves Tolerance by Increasing the Activity of Antioxidant Enzymes
}

\author{
Yihang Zhao, Yupeng Yang, Jingwen Jiang, Xiaomeng Zhang, Zewang Ma, Lingdong Meng, Guowen Cui \\ and Xiujie Yin *
}

check for updates

Citation: Zhao, Y.; Yang, Y.; Jiang, J.; Zhang, X.; Ma, Z.; Meng, L.; Cui, G.; Yin, $X$. The Caucasian Clover Gene TaMYC2 Responds to Abiotic Stress and Improves Tolerance by Increasing the Activity of Antioxidant Enzymes. Genes 2022, 13, 329. https://doi.org/10.3390/ genes13020329

Academic Editor: Bin Yu

Received: 15 December 2021

Accepted: 8 February 2022

Published: 10 February 2022

Publisher's Note: MDPI stays neutral with regard to jurisdictional claims in published maps and institutional affiliations.

Copyright: (C) 2022 by the authors. Licensee MDPI, Basel, Switzerland. This article is an open access article distributed under the terms and conditions of the Creative Commons Attribution (CC BY) license (https:// creativecommons.org/licenses/by/ $4.0 /)$.
College of Animal Science and Technology, Northeast Agricultural University, Harbin 150030, China; zhaoyh9712@163.com (Y.Z.); S210501072@neau.edu.cn (Y.Y.); jjw990824@163.com (J.J.); zhangxiaomeng20190@163.com (X.Z.); S210502008@neau.edu.cn (Z.M.); menglingdong0510@163.com (L.M.); cuigw603@126.com (G.C.)

* Correspondence: yinxiujie@neau.edu.cn

\begin{abstract}
Abiotic stress affects metabolic processes in plants and restricts plant growth and development. In this experiment, Caucasian clover (Trifolium ambiguum M. Bieb.) was used as a material, and the CDS of TaMYC2, which is involved in regulating the response to abiotic stress, was cloned. The CDS of TaMYC2 was 726 bp in length and encoded 241 amino acids. The protein encoded by TaMYC2 was determined to be unstable, be highly hydrophilic, and contain 23 phosphorylation sites. Subcellular localization results showed that TaMYC2 was localized in the nucleus. TaMYC2 responded to salt, alkali, cold, and drought stress and could be induced by IAA, GA, and MeJA. By analyzing the gene expression and antioxidant enzyme activity in plants before and after stress, we found that drought and cold stress could induce the expression of TaMYC2 and increase the antioxidant enzyme activity. TaMYC2 could also induce the expression of ROS scavenging-related and stress-responsive genes and increase the activity of antioxidant enzymes, thus improving the ability of plants to resist stress. The results of this experiment provide references for subsequent in-depth exploration of both the function of TaMYC2 in and the molecular mechanism underlying the resistance of Caucasian clover.
\end{abstract}

Keywords: Caucasian clover; TaMYC2; abiotic stress; clone; antioxidant enzyme

\section{Introduction}

Caucasian clover (T. ambiguum B.) is a perennial legume with a long crown [1,2]. This species is native to the cold Russian Caucasus, eastern Turkey, and northern Iran [3]. Caucasian clover can be cloned and propagated via rhizomes [4,5]. This species has strong adaptability and good resistance to drought, cold, and grazing [6]. Because of the harsh natural environment in which this species originated, the cold resistance of Caucasian clover is relatively strong [7]. Previously, our research group jointly used RNA-Seq and PacBio high-throughput sequencing technology to sequence the transcriptome of Caucasian clover and identified the genes related to the rhizome development [8]; this information in turn provided a rich genetic resource for the study of rhizome characteristics and the regulatory mechanism of stress resistance in Caucasian clover.

Abiotic stress such as drought, cold, and salt stress limits the growth and development, geographic distribution, yield, and quality of plants [9]. Abiotic stress affects the metabolic process of plants and limits the growth and development of plants at various stages [10-12]. Cold and drought are two common and critical abiotic stresses that can cause membrane damage, peroxidation, and accelerated senescence [13]. Plants employ complex physiological mechanisms for adapting and resisting abiotic stress [14]. Transcription factor (TF) families such as CBF [15], AP2, DREB [16], bHLH [17], and NAC [18] families, involved in 
this response, have also been gradually revealed. The expression of the genes encoding these TFs is often induced by abiotic stress, and these TFs also play an important regulatory role in plants.

bHLH TFs constitute the second major type of regulatory protein in plants [19]. These TFs have a specific bHLH domain, and they are involved in plant growth and development of plants and the response to abiotic stress [19]. MYC2 TFs are types of bHLH TFs and are important regulators of the jasmonic acid (JA) signaling pathway [20]. MYC2 TFs act as regulatory centers through the integration of multiple signaling pathways, which in turn affects various endogenous and exogenous signals that ultimately affect plant growth and development [21]. At the same time, these TFs participate in regulating the response of plants to abiotic stress [22]. Srivastava et al. found that MYC2s, which are component of the cytokinin signaling pathway, play an important role in the development of Arabidopsis seedlings [23]. Moreover, the MKK3-MPK6-MYC2 module positively regulates the biosynthesis and signal transduction of abscisic acid (ABA) in Arabidopsis [24], and MYC2s in Brassica napus regulate water loss and drought resistance by regulating stomatal opening and closing [25].

The use of plants with strong stress resistance (such as Caucasian clover) as research objects is effective for elucidating the comprehensive stress resistance mechanism in-depth to effectively improve and enhance plant stress resistance. However, research on the molecular mechanism underlying the stress resistance mechanism in Caucasian clover is lacking. Studies on MYC2s have mostly focused on JA signal transduction, but there are few studies related to abiotic stress [26]. In the present experiment, Caucasian clover was used as a material, and its TaMYC2 gene was cloned. Bioinformatic analysis and expression pattern analysis data of TaMYC2 in response to abiotic stress provide references for mining the function of TaMYC2 and for studying the molecular mechanisms of plant stress resistance. TaMYC2 responded to cold, drought, alkali, and salt stresses. TaMYC2 expression was also induced by indoleacetic acid (IAA), gibberellin $\left(\mathrm{GA}_{3}\right)$, and methyl jasmonate (MeJA). Lastly, TaMYC2 overexpression in tobacco significantly improved tolerance to drought and cold.

\section{Materials and Methods}

\subsection{Plant Materials, Growth Conditions, and Stress Treatments}

Full, uniform seeds of Caucasian clover were collected and sown in vermiculite after the seed coats were polished with sandpaper. The seeds were cultivated at $25^{\circ} \mathrm{C}$ under a $16 \mathrm{~h}$ photoperiod for 5 weeks, and Hoagland nutrient solution was applied every other day. Four Caucasian clover seedlings cultivated for 40 days were subjected to $4{ }^{\circ} \mathrm{C}, 150 \mathrm{mmol} / \mathrm{L}$ $\mathrm{NaCl}, 150 \mathrm{mmol} / \mathrm{L} \mathrm{NaHCO}_{3}$, or 15\% PEG-6000, and sampling was performed at $3 \mathrm{~h}, 6 \mathrm{~h}$, $12 \mathrm{~h}, 24 \mathrm{~h}$, and $48 \mathrm{~h}$ in each treatment. Other Caucasian clover seedlings were sprayed with $100 \mu \mathrm{mol} / \mathrm{L}$ IAA, GA 3 , and MeJA, and samples were taken at $3 \mathrm{~h}, 6 \mathrm{~h}, 12 \mathrm{~h}$, and $24 \mathrm{~h}$ in each treatment. Untreated plant materials of the same growth stage were used as controls (CKs). Each treatment involved three replications. Samples were taken from the roots, stems, and leaves of plants in each treatment, wrapped in aluminum foil, flash-frozen in liquid nitrogen, and then stored at $-80^{\circ} \mathrm{C}$.

\subsection{Cloning of the TaMYC2 Gene and Quantitative Real-Time PCR (qRT-PCR) Analysis of Gene Expression}

Total RNA was extracted using an Ultrapure RNA Kit (CWBIO, Taizhou, China). The cDNA template for reverse transcription PCR was synthesized using HiScript II Reverse Transcriptase (Vazyme, Nanjing, China). The coding DNA sequence (CDS) of TaMYC2 was obtained according to the results of transcriptome sequencing, and the primers used for cloning were designed using Primer 5 software (Table S1). Based on the cDNA template, $2 \times$ Taq Master Mix (Vazyme, Nanjing, China) was used for PCR amplification. The PCR product was electrophoresed on a 1\% agarose gel, and the target fragment was recovered with a FastPure Gel DNA Extraction Mini Kit (Vazyme, Nanjing, China). The recycled 
product was cloned into a pCE2 TA/Blunt-Zero vector (Vazyme, Nanjing, China) and sequenced for confirmation.

With cDNA used as a template, real-time fluorescence quantification was performed using internal reference and fluorescence quantification primers (Table S1). All the qRT-PCR analyses were performed using a ChanQ Universal SYBR qPCR Master Mix Kit according to the manufacturer's instructions, and the relative gene expression was calculated using the $2^{-\Delta \Delta \mathrm{Ct}}$ method.

\subsection{Bioinformatic Analysis}

The NCBI BLASTP program was used to search for homologous sequences of TaMYC2. DNAMAN was then used to compare the amino-acid sequence of TaMYC2 with those of other species. A phylogenetic tree was constructed using ClustalX 2.1 and MEGA 5. Domain prediction of TaMYC2 was carried out by SMART. The physicochemical properties, hydrophilicity, and phosphorylation sites of the amino acids were analyzed by ProtParam, ProtScale, and NetPhos 3.1.

\subsection{Construction of TaMYC2 Overexpression and Transient Expression Vectors in Tobacco}

Overexpression and instantaneous-expression primers (Table S1) were used for PCR and gel recovery to obtain the inserted fragments. pCAMBIA1300-35S-sGFP plasmids were linearized by double digestion with Bam HI and SacI (Figure S1). Overexpression and instantaneous-expression vectors were obtained by recombination of the inserted fragments and vectors, respectively. The vectors were transferred into Escherichia coli DH5 $\alpha$ and cultured for $12 \mathrm{~h}$. Several individual clones were selected for use in PCR detection and sequence comparison. The plasmid extracted from the bacterial solution and with the correct sequencing result was transformed into Agrobacterium EHA105 by the freezethaw method, after which the bacteria were spread onto double-resistant YEB media that included kanamycin and rifampin for selection. After $60 \mathrm{~h}$ of culture, a few individual colonies were selected for PCR verification.

\subsection{Subcellular Localization}

Seeds of Nicotiana benthamiana were sown in a mixture of vermiculite and potting soil (1:3). Each tobacco plant was then transplanted into a separate pot after the seeds germinated and was watered every day. A solution of transformed bacteria (after being cultured for 1 month) was diluted with buffer solution and then injected into the abaxial side of tobacco leaves with a needle. The infected leaf tissue was obtained after the plants were placed in the dark for 2 days. The leaf sections were observed with a confocal laser microscope.

\subsection{TaMYC2-Overexpressing Tobacco}

Sterilized Nicotiana tabacum L. 'K326' seeds were transferred to culture media. After the seeds had germinated and grown for 28 days, their leaves were taken as explants for preculture. Agrobacterium cells containing the plasmid with the target gene were cultured to an appropriate concentration and then used for infection and cocultivation of explants. The cocultured tobacco leaves were induced to form calli, and rooting was induced after two hygromycin-based selections. Then, the obtained plants were subjected to PCR to detect and obtain $\mathrm{T}_{0}$ tobacco plants. Eight transgenic lines were successfully identified, and three of them were selected for subsequent experiments (Figure S2). These three transgenic tobacco plants were transplanted into soil and cultivated until they produced seeds, which were harvested. The harvested seeds were placed in media that included hygromycin to germinate for selection, and the germinated seedlings were subjected to PCR detection to obtain $\mathrm{T}_{1}$-transformed TaMYC2-overexpressing tobacco plants, which were transplanted into soil for cultivation. 


\subsection{Physiological Measurements}

TaMYC2-overexpressing tobacco and wild-type (WT) tobacco cultivated for 28 days were cultivated at $4{ }^{\circ} \mathrm{C}$ for 7 days to simulate cold stress and continuously irrigated with $100 \mathrm{~mL}$ of $15 \%$ PEG-6000 to simulate drought stress for 7 days. The leaves of plants exposed to $\mathrm{CK}$, cold, and drought-stress conditions were sampled from the WT and three transgenic lines (L1, L2, and L3). There were three biological replicates of each WT, L1, L2, and L3 plant. Malondialdehyde (MDA) accumulation was measured using the thiobarbituric acidbased method [27], and the proline (Pro) content was determined by the acid ninhydrin method [27]. The chlorophyll content was measured as described by Feng et al. [28]. For the enzyme activity assays, the superoxide dismutase (SOD) activities were determined by measuring the inhibition rate of the enzyme to $\mathrm{O}_{2}{ }^{-}$produced by xanthine morpholine via xanthine oxidase; an SOD kit (Keming, Suzhou, China) was used for this. The catalase (CAT) activity was measured on the basis of the degradation of $\mathrm{H}_{2} \mathrm{O}_{2}$ at $405 \mathrm{~nm}$ via a CAT kit (Keming, Suzhou, China). Similarly, the peroxidase (POD) activity was measured on the basis of the change in absorbance at $420 \mathrm{~nm}$ caused by catalysis of $\mathrm{H}_{2} \mathrm{O}_{2}$; a POD kit (Keming, Suzhou, China) was used for this. Three technical replications were included for all index determinations.

\subsection{Statistical Analysis}

Excel 2019 was used to organize the data and create column charts. One-way analysis of variance was performed via SPSS 22.0, and Duncan's method was used for multiple comparisons.

\section{Results}

\subsection{Cloning of the TaMYC2 Gene from Caucasian Clover}

Total RNA of Caucasian clover was extracted (Figure S3a) and reverse-transcribed into cDNA. The quality of cDNA was verified using internal reference gene primers (Table S1, Figure S3b). Forward and reverse primers for cloning the CDS of TaMYC2 were designed according to the transcriptomic data, (Table S1). RT-PCR technology was used to amplify the CDS of TaMYC2 (Figure S3c), and the amplified products were cloned into a T vector following gel recovery. Sequencing revealed that the CDS of TaMYC2 was $726 \mathrm{bp}$ in length and encoded 241 amino acids (Table S2).

\subsection{Bioinformatic Analysis of TaMYC2}

The amino-acid sequence of TaMYC2 was uploaded to the SMART website for domain prediction, and the results showed that TaMYC2 contains an HLH domain located between residues 69 and 118 (Figure 1a). ProtParam was used to analyze the physicochemical properties of the TaMYC2 peptide: The molecular weight of $\mathrm{C}_{1160} \mathrm{H}_{1907} \mathrm{~N}_{333} \mathrm{O}_{368} \mathrm{~S}_{8}$ was 26663.39 KD, and the isoelectric point was 7.77. The most abundant amino acid was leucine, which reached $11.2 \%$, and the least abundant was cysteine at only $0.4 \%$. The aminoacid sequence of TaMYC2 comprises 34 negatively charged aspartic acid and glutamic acid residues and 35 positively charged arginine and lysine residues. The protein was considered unstable (instability index 38.42), and the lipid index was 87.80 . The amino-acid sequence of TaMYC2 was analyzed by NCBI Protein BLAST and compared with those of Trifolium pratense, Medicago truncatula, Arabidopsis thaliana, and Cicer arietinum by DNAMAN (Figure 1b). A phylogenetic tree was constructed by MEGA 5, which revealed that TaMYC2 was most closely genetically related to the MYC2 protein from red clover (Figure 1c).

The phosphorylation sites of TaMYC2 were predicted using the NetPhos 3.1 website (Figure S4a). There were a total of 23 phosphorylation sites, including 19 phosphorylation sites involving serine, three phosphorylation sites involving threonine, and one phosphorylation site involving tyrosine. Analyses of the hydrophilicity and hydrophobicity of the TaMYC2 protein were performed via the ProtScale website. It can be seen from the figure that most amino acids have negative values, and many negative amino acids have strong hydrophilic properties. Therefore, it can be inferred that TaMYC2 is a hydrophilic protein 
(Figure S4b). Moreover, transmembrane domain analysis showed that the TaMYC2 protein does not contain any transmembrane domains (Figure S4c). Additionally, TaMYC2 is not a secreted protein and contains no signal peptide (Figure S4d).

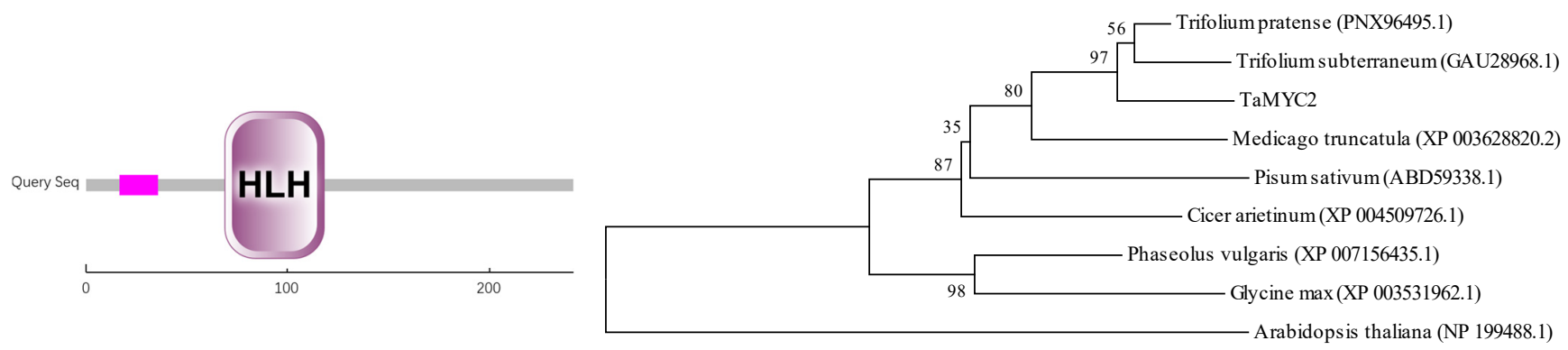

(a)

(b)

HLH domain
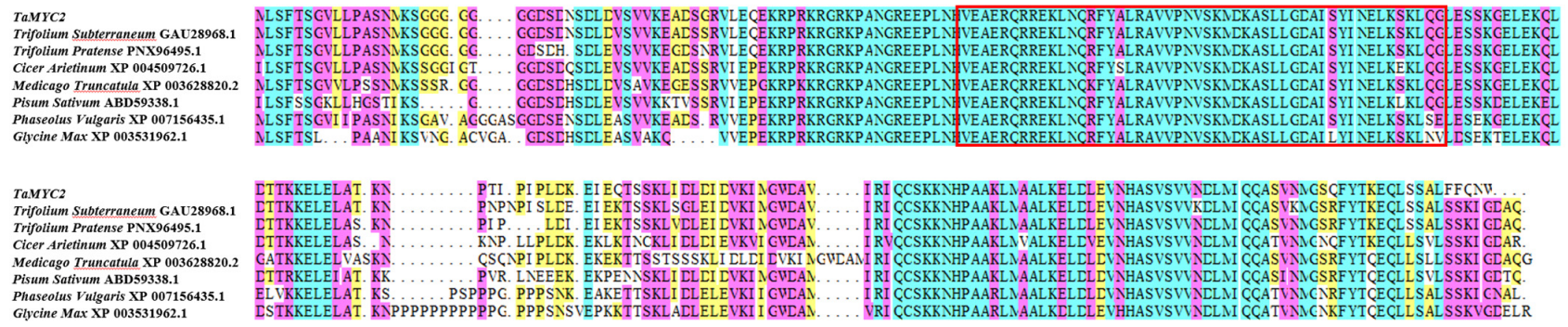

(c)

Figure 1. Bioinformatic analysis of TaMYC2 in Caucasian clover. (a) SMART domain analysis. (b) Phylogenetic analysis of TaMYC2 in Caucasian clover. (c) Multispecies homologous amino-acid sequence alignment.

\subsection{Expression Analysis of TaMYC2 in Response to Abiotic Stress}

The expression of TaMYC2 changed in response to drought, salt, alkali, and cold stress (Figure 2). Under 15\% PEG-6000-simulated drought stress, the variation of TaMYC2 expression in different plant tissues tended to be different. The expression level of TaMYC2 in the roots of PEG-6000-treated plants was significantly higher than that of the CK plants $(p<0.05)$, but the expression level of TaMYC2 in the stems and leaves significantly decreased $(p<0.05)$ after PEG treatment for $3 \mathrm{~h}$ and $6 \mathrm{~h}$. After PEG treatment for $12 \mathrm{~h}$, the gene expression in the leaves reached the highest level, and the gene expression in the stems increased to the same level as that in the CK, but the gene expression in the roots significantly decreased compared with that at $3 \mathrm{~h}$ and $6 \mathrm{~h}(p<0.05)$. After PEG treatment for $48 \mathrm{~h}$, the expression of TaMYC2 in the leaves was the lowest, and the expression of TaMYC2 in the roots was the highest.

Under $150 \mathrm{mmol} / \mathrm{L} \mathrm{NaCl}$ stress, the expression of TaMYC2 in the leaves and roots of the treated plants was significantly higher than that in the CK $(p<0.05)$, and the expression of TaMYC2 in the stems was significantly lower than that in the CK after $3 \mathrm{~h}(p<0.05)$. The expression level of TaMYC2 in the stems further decreased after $6 \mathrm{~h}$ of $\mathrm{NaCl}$ treatment, while the expression level of TaMYC2 in the roots further increased to a level that was significantly more than that in the other treatments $(p<0.05)$. After $12 \mathrm{~h}$ of $\mathrm{NaCl}$ treatment, the gene expression levels in all the evaluated tissues significantly increased compared with the levels of the CK $(p<0.05)$, and the expression level in the stems was significantly higher than that in the other treatments $(p<0.05)$. The expression of TaMYC2 in the leaves was significantly higher after $24 \mathrm{~h}$ of $\mathrm{NaCl}$ treatment than after the other treatments $(p<0.05)$, and the expression of TaMYC2 in the leaves of plants after $48 \mathrm{~h}$ of $\mathrm{NaCl}$ treatment was significantly lower than that of the CK plants $(p<0.05)$. 

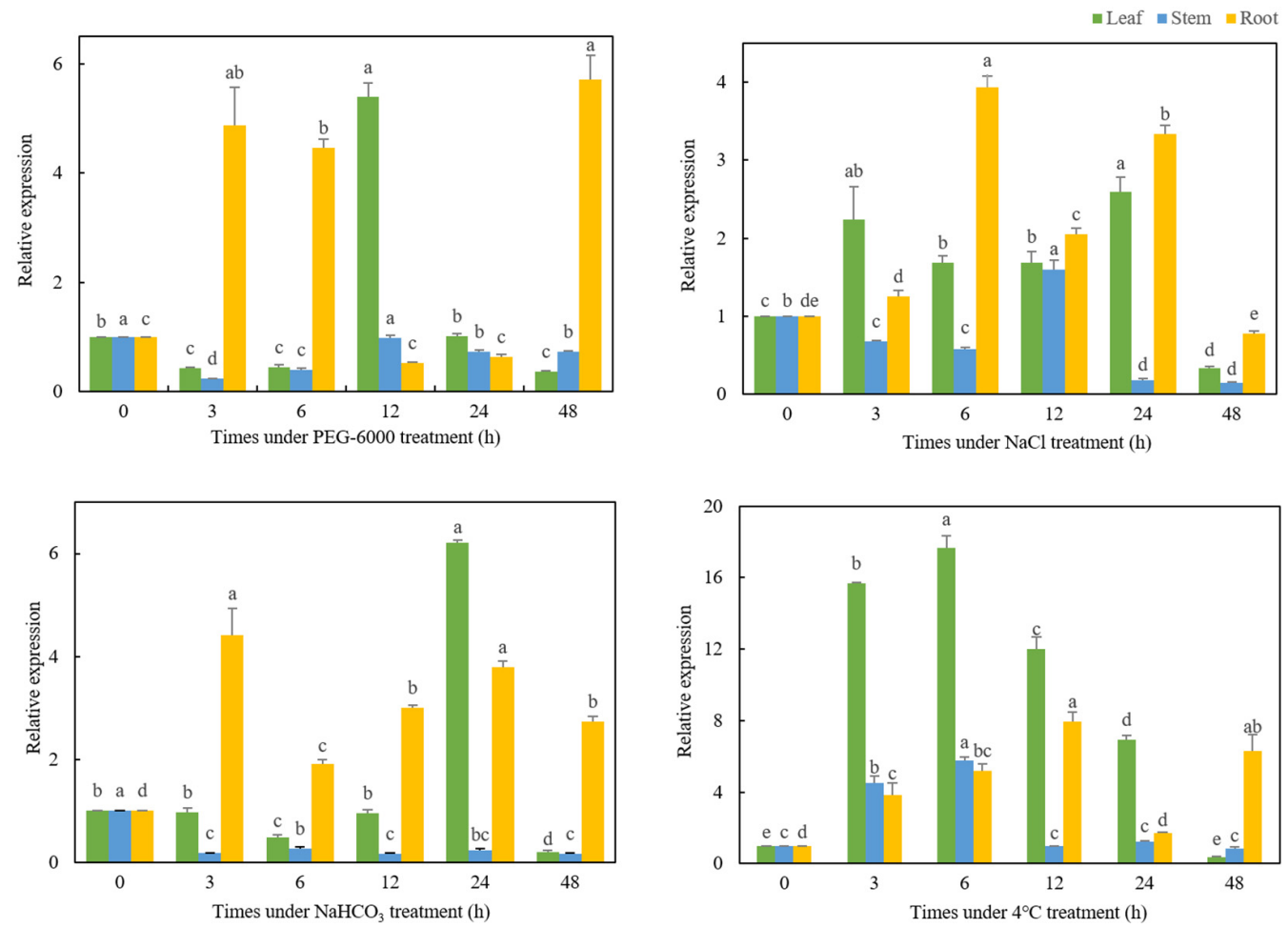

Figure 2. Expression analysis of TaMYC2 in Caucasian clover under abiotic stress. The different lowercase letters indicate significant differences under different treatment times for the same tissue $(p<0.05)$. The same scheme applies to the figures shown below.

Under $150 \mathrm{mmol} / \mathrm{L} \mathrm{NaHCO}_{3}$ alkali stress, the expression level of TaMYC2 in the roots of the plants in the five treatment groups was significantly higher than that in the CK $(p<0.05)$, and the highest expression level was detected after $3 \mathrm{~h}$ of treatment. The expression level of TaMYC2 in the stems of the treated plants was significantly lower than that of CK plants $(p<0.05)$. Among the plants in the five treatment groups, the expression level of TaMYC2 in the leaves of the plants in the $24 \mathrm{~h}$ group was significantly higher than that in the CK group $(p<0.05)$.

Under cold stress, with increasing stress duration, the expression of TaMYC2 in the three tissues first increased and then decreased. Under $4{ }^{\circ} \mathrm{C}$ for $3 \mathrm{~h}$ and $6 \mathrm{~h}$, the expression of TaMYC2 in the three tissues was significantly higher than that of the CK $(p<0.05)$, and the gene expression in the leaves and stems peaked when the plants were exposed $4{ }^{\circ} \mathrm{C}$ for $6 \mathrm{~h}$. The expression of TaMYC2 in the roots peaked when the plants were exposed to $4{ }^{\circ} \mathrm{C}$ for $12 \mathrm{~h}$ and was significantly higher than that in the other treatments $(p<0.05)$, while the expression of TaMYC2 in the leaves and stems gradually decreased beginning at $12 \mathrm{~h}$, reaching the lowest level at $48 \mathrm{~h}$.

\subsection{Analysis of TaMYC2 Expression Patterns in Response to Hormone Treatments}

The expression level of TaMYC2 in response to IAA, GA 3 , and MeJA treatments changed drastically, and the change trends under the three treatments were different (Figure 3). The expression of TaMYC2 in the stems and leaves under the $3 \mathrm{~h} \mathrm{IAA}$ treatment was significantly higher than that under the other treatments $(p<0.05)$, while the expression in the roots in the treated plants was significantly lower than that in the CK plants $(p<0.05)$. The expression of TaMYC2 in the stems and leaves was the lowest when IAA treatment was applied for $6 \mathrm{~h}$. The expression of TaMYC2 in the roots decreased to the lowest value after IAA treatment for $24 \mathrm{~h}$, which was significantly lower than that of the CK $(p<0.05)$. Under $\mathrm{GA}_{3}$ treatment, the expression of TaMYC2 in the leaves and stems first increased and then decreased with increasing treatment duration. The expression levels of TaMYC2 in the leaves and stems were the highest upon treatment for $6 \mathrm{~h}$, the levels of which were 
approximately 10 and 12 times that of the $C K$, respectively. Except at $12 \mathrm{~h}$, the expression of TaMYC2 in the roots of the $\mathrm{GA}_{3}$-treated plants was significantly lower than that of the CK plants at each treatment time $(p<0.05)$. Under MeJA treatment, the expression of TaMYC2 in the leaves and stems of the treated plants increased first and then decreased with increasing treatment time, and the expression of TaMYC2 in the leaves and stems of plants at each treatment time was significantly higher than that of the CK plants $(p<0.05)$. The expression of TaMYC2 in the leaves was the highest at $3 \mathrm{~h}$, the level of which was approximately 90 times that of the CK, and the expression of TaMYC2 in the stems was the highest at $6 \mathrm{~h}$, the level of which was approximately 40 times that of the CK. The expression of TaMYC2 in the roots was the lowest after $3 \mathrm{~h}$ of treatment with MeJA and was significantly lower than that of the CK plants $(p<0.05)$, but then TaMYC2 expression increased to the highest value at $12 \mathrm{~h}$ treatment with MeJA, the level of which was significantly higher than that of the CK $(p<0.05)$.
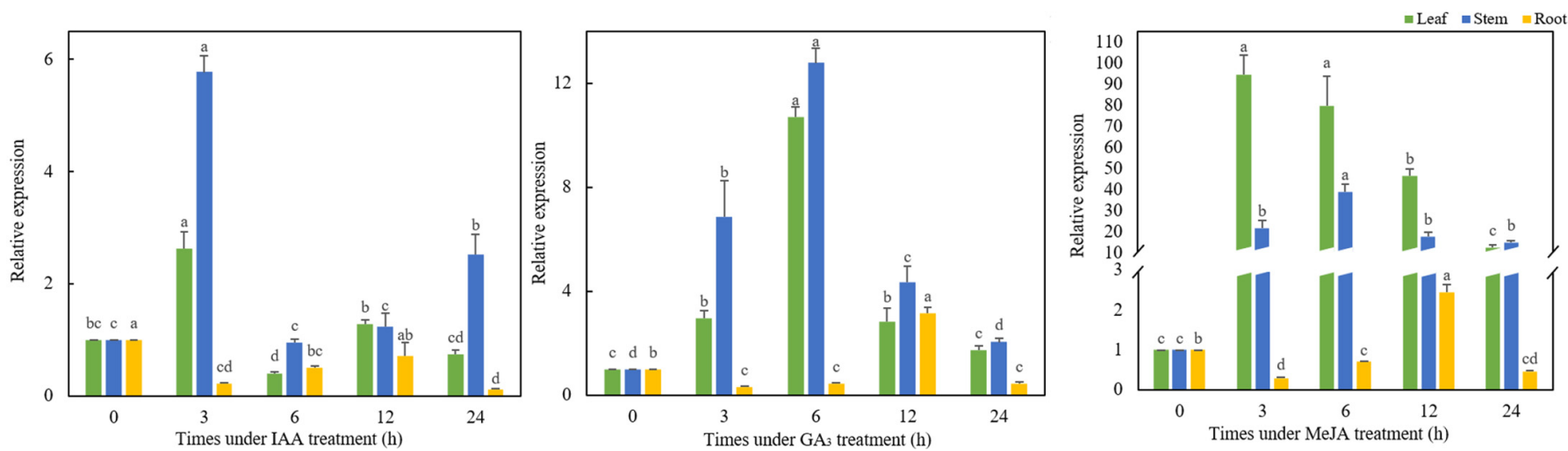

Figure 3. Analysis of TaMYC2 expression patterns in response to various hormone treatments.

\subsection{The TaMYC2 Protein Localizes to the Nucleus}

pCBMBIA1300-35S-sGFP plasmids were digested with BamHI and SacI, and the vectors were linearized. The target fragment was amplified with transient-expression primers using the pCE2-TaMYC2 plasmid as a template, and the tobacco transient expression vector p1300sGFP-TaMYC2 was obtained after recombination. The resulting tobacco transient expression vector construct was transformed into Agrobacterium EHA105, and the transformed cells were injected into tobacco. The expression position of TaMYC2 was observed via confocal laser microscopy, and the results showed that TaMYC2 was expressed in the nucleus (Figure 4).

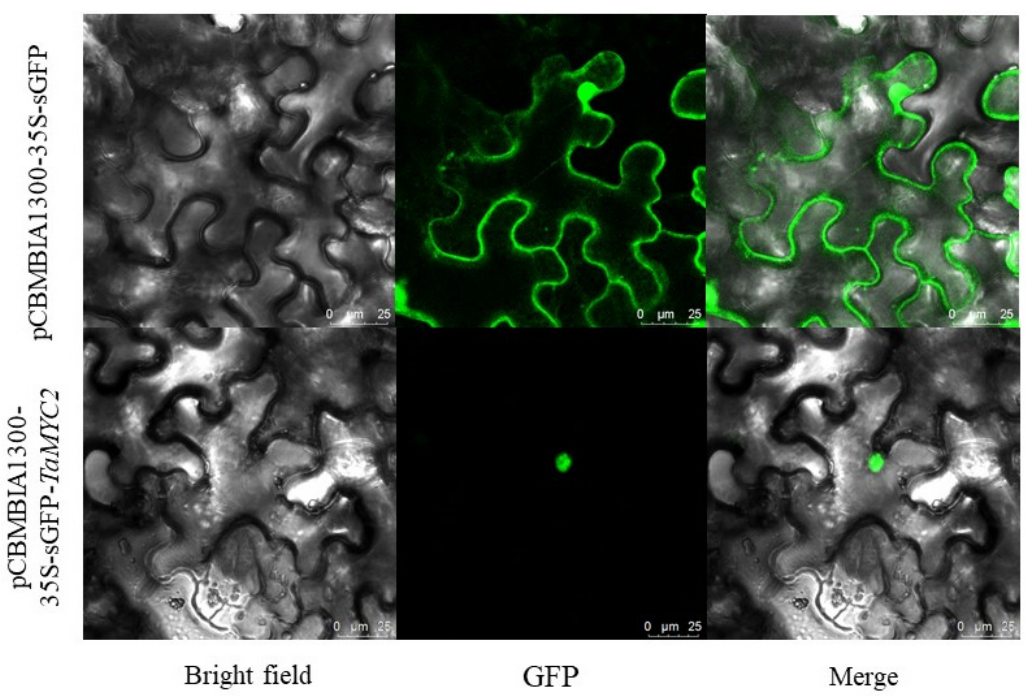

Figure 4. Subcellular localization of TaMYC2 in tobacco. 


\subsection{Functional Verification of TaMYC2-Overexpressing Tobacco in Response to Abiotic Stress}

After 7 days of being exposed to $4{ }^{\circ} \mathrm{C}$, transgenic plants were growing well, and there was no obvious change in phenotype compared with that of the previous treatment. However, the WT plants showed obvious wilting (Figure 5a). Under the same cold stress, the MDA content of the WT plants increased significantly, although the increase in MDA content of the transgenic plants was lower. The MDA content of the transgenic plants was significantly lower than that of the WT plants $(p<0.05)$, and the MDA content of the WT plants was approximately twice that of the transgenic plants (Figure 5b). The Pro content of the WT plants decreased under cold stress, while the Pro content of the transgenic plants increased slightly. The Pro content of the transgenic plants was significantly higher than that of the WT plants $(p<0.05)$ (Figure $5 c$ ). Under cold stress, the SOD, CAT, and POD activities of the transgenic plants were significantly higher than those of the WT plants $(p<0.05)$ (Figure 5d). The SOD activity in the WT plants under cold stress decreased, while the SOD activity in the transgenic plants increased. Under cold stress, the POD activity in the WT plants increased slightly, while the POD activity in the transgenic plants increased significantly, reaching a level twice that of the WT plants. Lastly, the CAT activity in the WT plants and transgenic plants increased under cold stress, but the CAT activity in the transgenic plants increased to a greater degree.

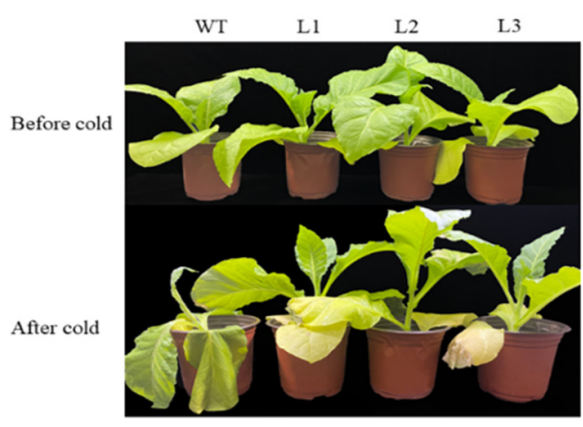

(a)

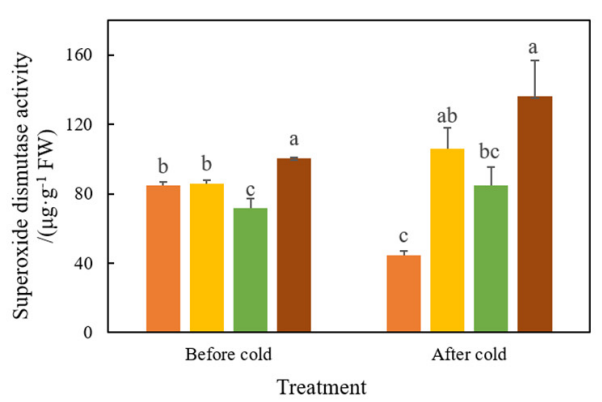

Treatment

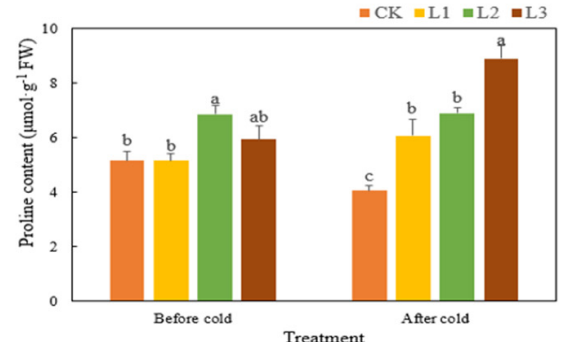

(b)

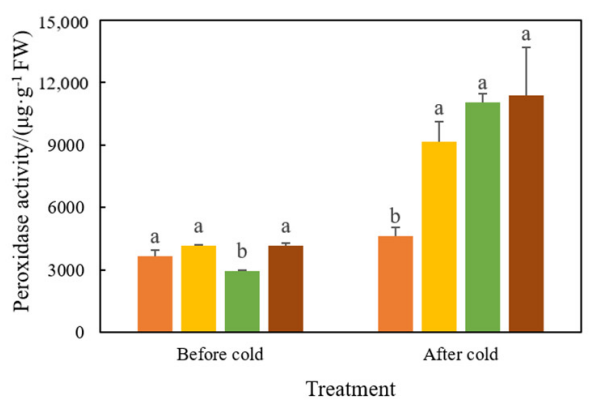

(d)

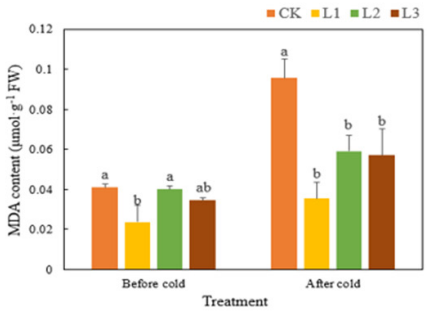

(c)

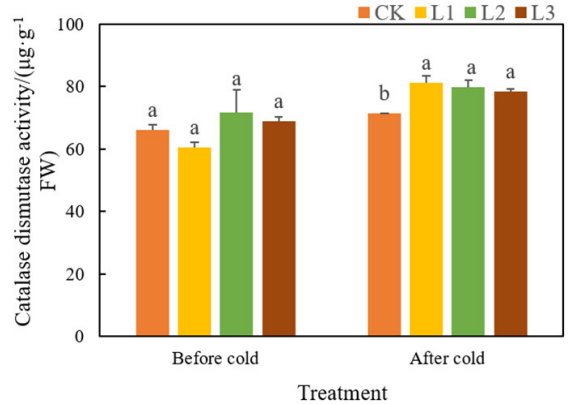

Figure 5. Functional verification of TaMYC2-overexpressing tobacco in response to cold stress. The different lowercase letters indicate significant differences under the different treatments for the same plant $(p<0.05)$; the same scheme applies to the figures below. Comparisons of phenotypes (a), MDA contents (b), Pro contents (c), and antioxidant enzyme activities (d) between WT and transgenic tobacco under cold stress.

After 15\% PEG-6000 treatment for 7 days, the leaves of both the WT plants and the transgenic plants were withered and wilted, but the wilting of the WT plants was more severe than that of the transgenic plants. At the same time, the growth of the WT plants was also suppressed, and the plant height and leaf size were obviously lower than those of the transgenic plants (Figure 6a). After 7 days of drought treatment, the content of chlorophyll $a$ in the WT plants was approximately the same, while the content of chlorophyll $b$ decreased. However, the chlorophyll $a$ content of the transgenic plants greatly increased. Under 
drought stress, the chlorophyll $a$ and chlorophyll $b$ contents of the transgenic plants were significantly higher than those of the WT plants $(p<0.05)$ (Figure $6 \mathrm{~b})$. In addition, under drought stress, the MDA content of the WT plants more than doubled, while the MDA content of the transgenic plants only slightly increased compared to the levels before the stress. The MDA content of the transgenic plants was significantly lower than that of the WT plants $(p<0.05)$ (Figure 6c). Moreover, under drought stress, the SOD, CAT, and POD activities of the transgenic plants were significantly higher than those of the WT plants $(p<0.05)$ (Figure 6d). However, after drought stress, the SOD activity in the WT plants decreased, while the SOD activity in the transgenic plants increased significantly. The POD activity in the WT plants increased, but the degree of increase in the transgenic plants was greater, approximately two to four times that of the WT plants. After drought stress, the CAT activity in the WT plants decreased, while the CAT activity in the transgenic plants increased, but the difference in activity between the two types was relatively small.

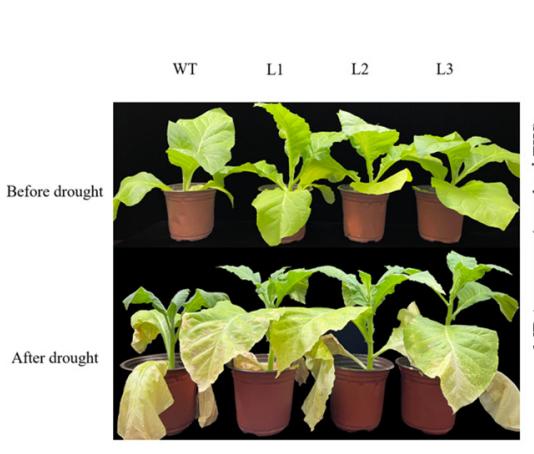

(a)

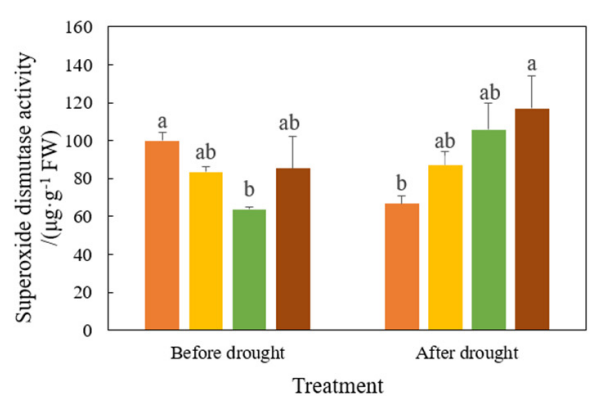

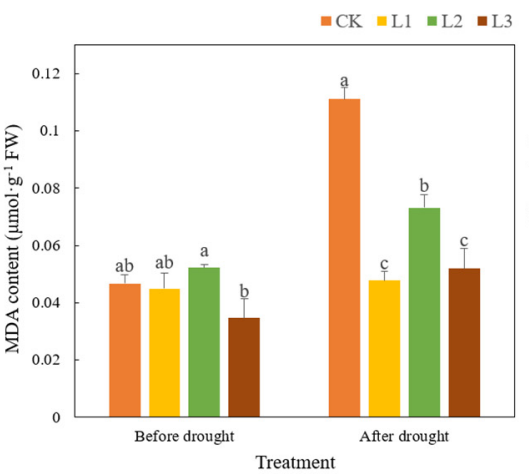

(b)

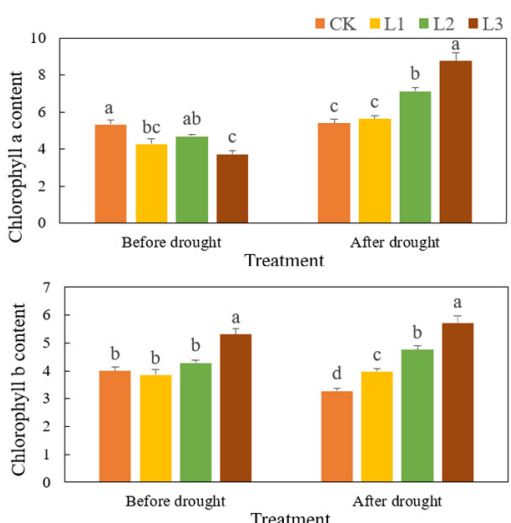

(c)
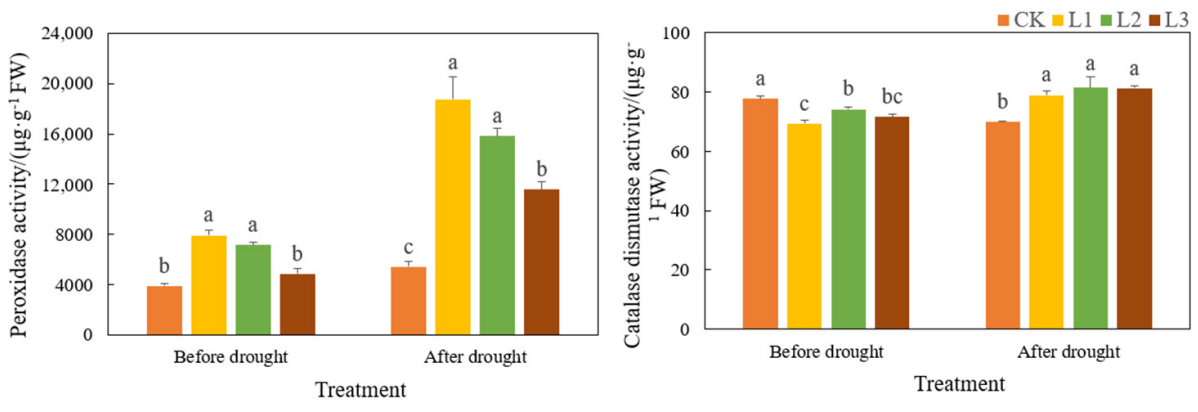

(d)

Figure 6. Functional verification of TaMYC2-overexpressing tobacco under drought stress. Comparisons of phenotypes (a), MDA contents (b), chlorophyll contents (c), and antioxidant enzyme activities (d) between WT and transgenic tobacco under drought stress.

\subsection{Expression Analysis of Reactive Oxygen Species (ROS) Scavenging-Related and} Stress-Responsive Genes in Transgenic and WT Plants before and after Treatment

After cold stress, the expression levels of NtSOD, NtCAT, NtLEA5, and NtERD10C in the WT tobacco and transgenic tobacco increased, but the gene expression level in the transgenic tobacco increased to a greater degree (Figure 7). Before and after cold stress, the expression of ROS scavenging-related and stress-responsive genes in the transgenic plants was significantly higher than that in the CK plants $(p<0.05)$. This indicates that the overexpression of TaMYC2 likely increases the induction of ROS scavenging-related and stress-responsive genes under cold stress. The expression changes of ROS scavengingrelated and stress-responsive genes in WT tobacco and TaMYC2-overexpressing tobacco before and after drought stress were similar to those before and after cold stress, respectively (Figure 8). Overexpression of TaMYC2 enhanced the induction of ROS scavenging-related 
and stress-responsive genes in response to drought stress. Drought stress also induced the expression of ROS scavenging-related and stress-responsive genes. However, the degree of induction of ROS scavenging-related and stress-responsive genes in the transgenic plants was higher than that in the WT plants.
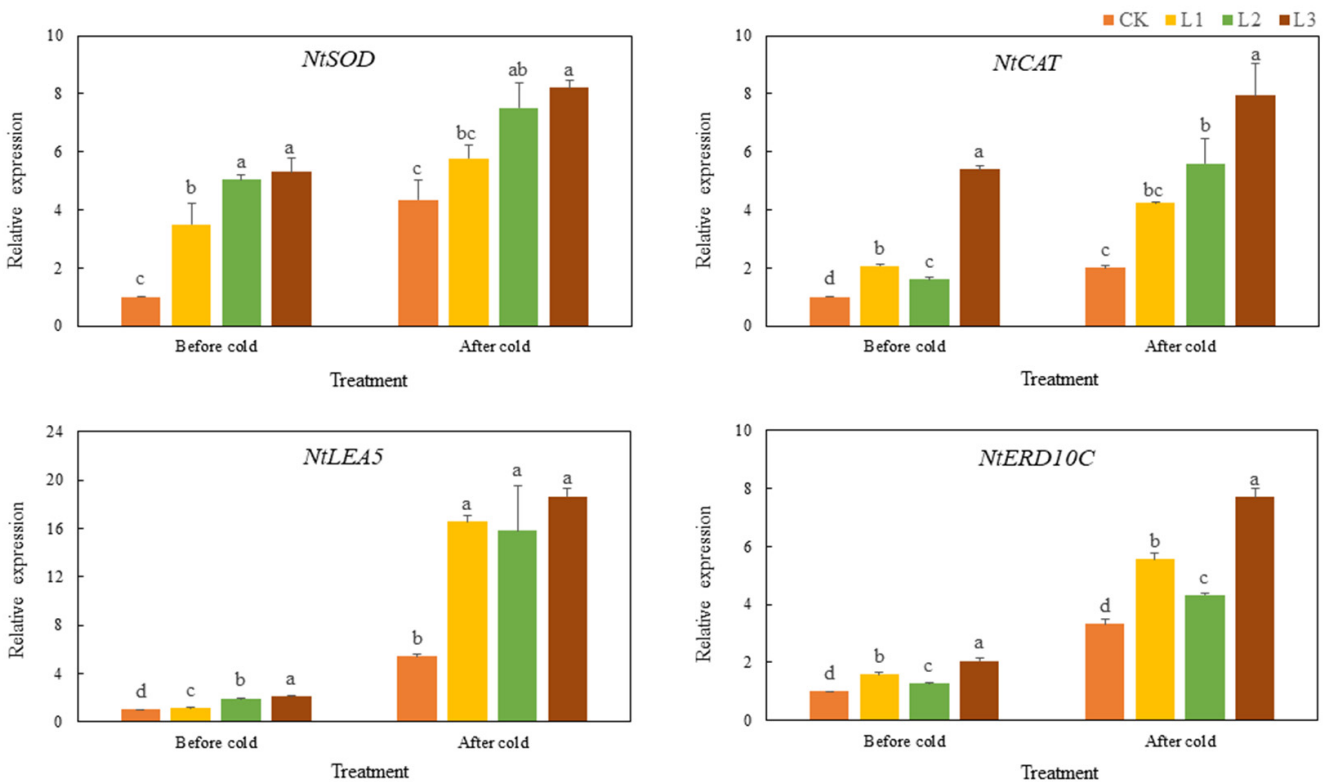

Figure 7. Analysis of the relative expression of ROS scavenging-related and stress-responsive genes under in response to stress.
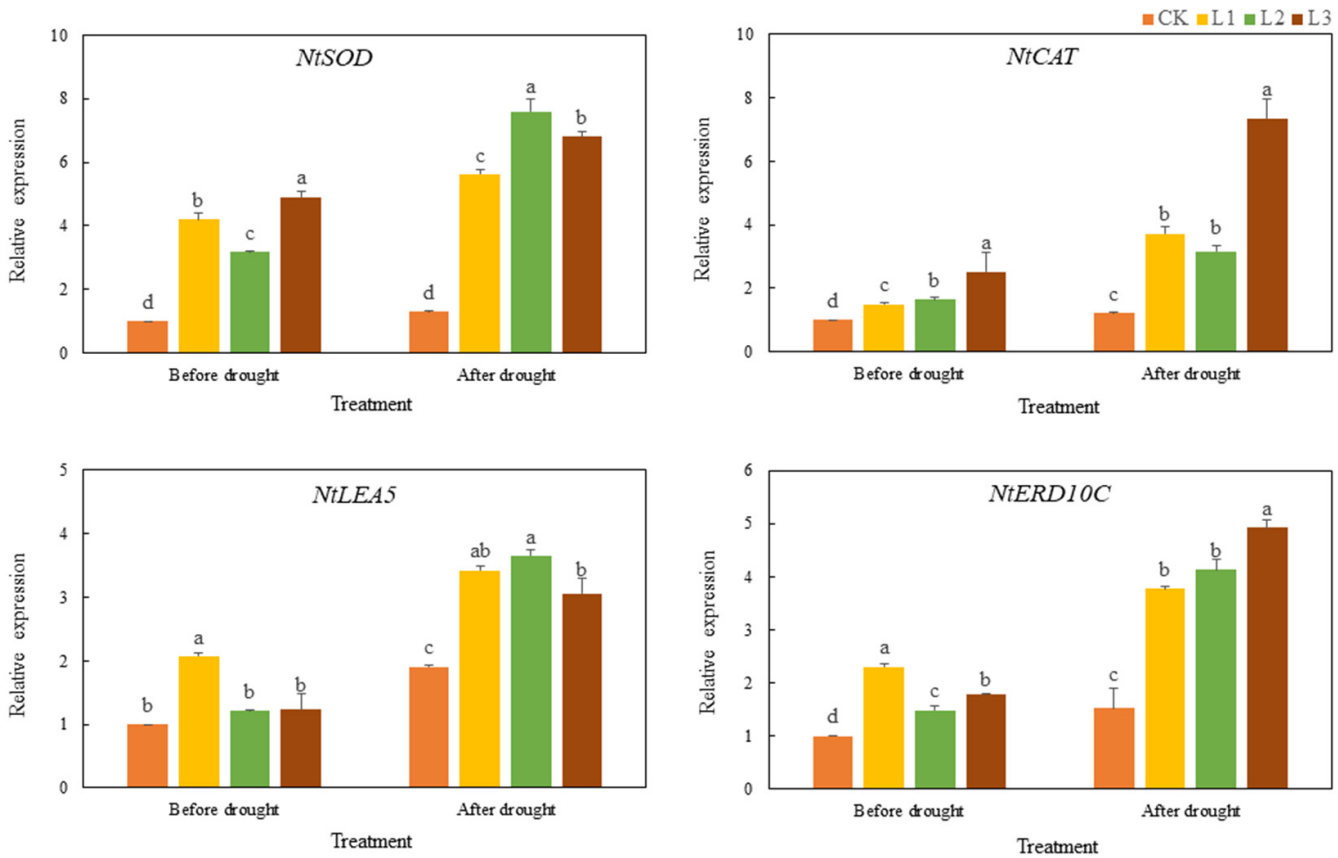

Figure 8. Analysis of the relative expression of ROS scavenging-related and stress-responsive genes in response to drought stress.

\section{Discussion}

Bioinformatic technology can be used to analyze the sequence of genes, determine the functions of genes, and improve the efficiency of genetic research [29]. In this study, RT-PCR was used to successfully clone the CDS of the Caucasian clover MYC2 gene according to transcriptomic data. The sequencing results after cloning were consistent with the 
predicted transcriptomic results, and the gene was named TaMYC2. The full-length CDS of TaMYC2 was determined to be $726 \mathrm{bp}$, encoding 241 amino acids. The MYC2 TF is a bHLH-type TF containing a bHLH domain [30,31]. The conserved bHLH domain consists of an alkaline region and the HLH region; the HLH region is located at the C-terminus of the bHLH domain, while the alkaline region is located at the N-terminus of the bHLH domain [32,33]. SMART domain analysis showed that the TaMYC2 gene has an HLH domain, which showed that the TaMYC2 gene belongs to the MYC2 TF family. The bHLH domain is mainly composed of hydrophobic residues that form two amphiphilic $\alpha$ helices, which also confirms the supposition that TaMYC2 is a hydrophobic protein according to the ProtScale website. MYC TFs are ubiquitous in plants. Our phylogenetic tree showed that TaMYC2 is highly homologous to MYC2 in red clover (which is in the same genus) and $M$. truncatula, which is also in the legume family, but that TaMYC2 has homology with MYC2 in A. thaliana.

Phytohormones are important regulators in plants and are highly important at all stages of plant growth and development [34]. MLC TFs are widespread in plants and animals and have a variety of regulatory functions, such as in JA signaling in plants [35]. By transforming $Z m M Y C 2$ from maize into A. thaliana, Jing Yefu et al. found that ZmMYC2 interacts with JA signal repressors, revealing that $Z m M Y C 2$ plays various regulatory roles in JA and auxin signal transduction in maize [36]. Studies have shown that MYC2 TFs are involved in the regulation of signal transduction involving ABA, JA, and other hormones and play important roles in plant growth and development [37]. Moreover, studies have shown that JA and ABA can induce the expression of MYC2s [38]. In the present study, we found that TaMYC2 expression in plant leaves and stems increased significantly in response to three exogenous hormones, while gene expression in the roots was induced to a lesser degree. This indicates that TaMYC2 in Caucasian clover leaves and stems is relatively sensitive to exogenous application of these three hormones. The expression pattern of TaMYC2 in the roots of Caucasian clover plants was quite different from the expression pattern in the leaves and stems. We speculate that this difference is due to differences in the regulatory mechanisms of plant hormones and to the low expression of the TaMYC2 gene in the roots. When $\mathrm{GA}_{3}$ and MeJA were applied exogenously, the expression of TaMYC2 in the Caucasian clover leaves and stems increased first and then decreased, which was consistent with the $M Y C 2$ expression pattern reported by Wang et al. in rape in response to exogenous application of ABA and JA [38]. Moreover, $\mathrm{GA}_{3}$ and MeJA within a certain period after treatment could induce the expression of TaMYC2 in Caucasian clover leaves and stems. Thus, TaMYC2 is not only involved in hormone signal transduction but also regulated by exogenous hormones.

Salt-alkaline stress is an important and common abiotic stress that can cause water stress, ion toxicity, and even plant death [39,40]. Deepanjali Verma et al. found that salt stress can activate $M Y C 2 \mathrm{~s}$ through the mitogen activated protein kinase (MAPK) cascade pathway and that MYC2s regulate the synthesis of Pro by regulating P5CS1 expression [41]. In the present study, salt stress induced the expression of TaMYC2 in the leaves and roots but inhibited its expression in the stems. Similarly, alkaline stress induced the expression of TaMYC2 in the roots but inhibited its expression in the stems. These results show that TaMYC2 responds differently to salt stress and alkali stress, which is especially true in the tissues whose sensitivity to the various stresses differed.

Drought stress inhibits the expansion of leaves, causes stomata to close, and reduces the photosynthetic rate and enzyme activities of plants [42,43]. Cold stress can severely affect the normal growth and development of plants and cause disorders involving plant metabolism. Cold stress can also disrupt the water balance in plants and destroy plant membrane systems [44]. In the present study, analysis of gene expression patterns revealed that TaMYC2 responds to $4{ }^{\circ} \mathrm{C}$ and polyethylene glycol (PEG) stress; thus, drought and cold stress can affect the expression of TaMYC2. Drought stress had a greater impact on the expression of TaMYC2 in the plant roots, while the impact in the stems and leaves was relatively small. Under cold stress, the expression of TaMYC2 in the three parts showed a 
trend of increasing first and then decreasing. This change trend was more consistent with the change trend of SOD and POD activity in plants under cold stress [45]. SOD, POD, and CAT are important antioxidant enzymes in plants that are involved in resistance to adversity and remove active oxygen $[46,47]$. Therefore, TaMYC2 may participate in the regulation of plant protection-related mechanisms, promote the production of plant protection-related enzymes, and enhance the ability of plants to resist low temperature stress.

In addition to the three common antioxidant enzymes mentioned above, MDA, Pro, chlorophyll $a$, and chlorophyll $b$ are important indicators to evaluate the tolerance of plants to cold and drought stress. Plant cell membranes can become disrupted by abiotic stress, and membrane permeability increases. The continuous accumulation of active oxygen eventually leads to the peroxidation of membrane lipids, resulting in the production of MDA $[48,49]$. Plants resist abiotic stress by increasing the content of osmotic adjustment substances such as Pro [50]. By measuring the physiological indicators of WT and transgenic tobacco under cold and drought stress, we found that the TaMYC2-overexpressing plants presented a lower degree of membrane lipid peroxidation and higher antioxidant enzyme activity than the WT plants did. Moreover, the transgenic plants had higher chlorophyll $a$ and chlorophyll $b$ contents under drought stress, as well as higher Pro contents under cold stress. These results indicate that TaMYC2-overexpressing plants have better resistance to abiotic stress than WT plants do. This also confirmed our previous hypothesis that TaMYC2 enhances plant resistance to stress by promoting the production of plant protection enzymes. The overexpression of TaMYC2 in response to abiotic stress could regulate antioxidant enzyme activity in plants and reduce the degree of peroxidation of plant membrane lipids.

Lastly, the expression of ROS scavenging-related and stress-responsive genes was measured in transgenic tobacco under drought and cold stress. Studies have shown that these genes or their homologous genes play roles in ROS scavenging- and stressrelated responses [51-54]. Overexpression of TaMYC2 could induce the expression of ROS scavenging-related and stress-responsive genes to a certain extent. At the same time, overexpression of TaMYC2 could increase the expression of ROS scavenging-related and stress-responsive genes under cold and drought stress, thereby enhancing the ability of the transgenic plants to respond to stress. On the basis of the above conclusions, we speculated that TaMYC2 was highly responsive to abiotic stresses such as cold and drought. Moreover, overexpression of TaMYC2 could help regulate antioxidant enzyme activity in plants and reduce the degree of peroxidation of plant membrane lipids. At the same time, TaMYC2 overexpression induced the expression of ROS scavenging-related and stress-responsive genes, enhanced the ability of plants to respond to stress, and increased antioxidant enzyme activities, thereby improving plant stress resistance.

\section{Conclusions}

In this experiment, the CDS of TaMYC2 of Caucasian clover was successfully cloned. After it was sequenced, the CDS of the gene was determined to be $726 \mathrm{bp}$ in length, encoding 241 amino acids. The protein encoded by TaMYC2 contains an HLH domain and was most closely phylogenetically related to the MYC2 protein from red clover. The protein encoded by TaMYC2 is unstable, highly hydrophilic, and contains 23 phosphorylation sites. Subcellular localization results showed that TaMYC2 was localized in the nucleus. TaMYC2 is expressed in response to salt, alkali, cold, and drought stress and is induced by three hormones, i.e., IAA, GA 3 , and MeJA. Under salt and alkali stress, TaMYC2 expression is induced in the roots, but it is inhibited in the stems. Drought and cold stress induced the expression of TaMYC2 and increased antioxidant enzyme activities in the plants. At the same time, TaMYC2 could also induce the expression of ROS scavenging-related and stress-responsive genes and increase the activity of antioxidant enzymes in plants, thus improving the ability of plants to resist stress. 
Supplementary Materials: The following supporting information can be downloaded at https:/ /www. mdpi.com/article/10.3390/genes13020329/s1: Figure S1. Schematic diagram of the pCAMBIA130035S-sGFP vector; Table S1. Primers used in this study; Figure S2. RNA electrophoresis, quality assessment of Caucasian clover CDNA, and results of PCR amplification of the TaMYC2 gene; Figure S3. Bioinformatic analysis of TaMYC2 in Caucasian clover; Table S2. The CDS and encoded amino-acid sequence of TaMYC2.

Author Contributions: Validation, Z.M.; methodology, X.Z.; formal analysis, J.J.; investigation, Y.Y. and L.M.; writing-original draft preparation, Y.Z.; writing-review and editing, X.Y.; project administration, G.C. All authors have read and agreed to the published version of the manuscript.

Funding: This research was funded by the Natural Science Foundation of Heilongjiang Province of China (LH2021C040), the National Natural Science Foundation of China (31802120), and the Research and Academic Backbone Fund Project of Northeast Agricultural University. The funders were not involved in the design of the experiment or in the drafts and revisions of the manuscript.

Institutional Review Board Statement: Not applicable.

Informed Consent Statement: Not applicable.

Conflicts of Interest: The authors declare no conflict of interest.

\section{References}

1. Lane, I.; Watkins, E.; Spivak, M. Turfgrass species affect the establishment and bloom of Kura clover (Trifolium ambiguum) in lawns. Hortscience 2019, 54, 824-828. [CrossRef]

2. Black, A.D.; Lucas, R.J. Caucasian clover was more productive than white clover in grass mixtures under drought conditions. NZGA 2000, 62, 183-188. [CrossRef]

3. Davis, P.H. Flora of Turkey and the East Aegean Islands. Q. Rev. Biol. 1965, 35, 103-104.

4. Sheaffer, C.C.; Marten, G.C. Kura clover forage yield, forage quality, and stand dynamics. Can. J. Plant. Sci. 1991, 71, 1169-1172. [CrossRef]

5. Taylar, N.L.; Smith, R.R. Kura Clover (Trifolium ambiguum M. B.) Breeding, Culture, and Utilization. Adv. Agron. 1997, 63, 153-178.

6. Brummer, E.C.; Moore, K.J. Persistence of perennial cool-season grass and legume cultivars under continuous grazing by beef cattle. Agron. J. 2000, 92, 466-471. [CrossRef]

7. Black, A.; Lucas, R.J.; Moot, D. Net photosynthesis rate and chlorophyII content of Caucasian and white clover leaves under different temperature regimes. Dep. Agric. Sci. 2015, 200-220.

8. Xiujie, Y.; Kun, Y.; Yihang, Z.; Yao, H.; Xu, L.; Taotao, H.; Jiaxue, L.; Guowen, C. Revealing the full-length transcriptome of caucasian clover rhizome development. BMC Plant Biol. 2020, 20, 429.

9. Rhaman, M.S.; Imran, S.; Karim, M.M.; Chakrobortty, J.; Mahamud, M.A.; Sarker, P.; Arif, M.T.U.; Robin, A.H.K.; Wenxue, Y.; Murata, Y.; et al. 5-aminolevulinic acid-mediated plant adaptive responses to abiotic stress. Plant Cell Rep. 2021, 40, 1451-1469. [CrossRef]

10. Haidong, L.; Jiquan, X.; Dongwei, G. Efficacy of planting date adjustment as a cultivation strategy to cope with drought stress and increase rainfed maize yield and water-use efficiency. Agric. Water Manag. 2017, 179, 227-235.

11. Sytar, O.; Brestic, M.; Zivcak, M.; Olsovska, K.; Kovar, M.; Hongbo, S.; Xiaolan, H. Applying hyperspectral imaging to explore natural plant diversity towards improving salt stress tolerance. Sci. Total Environ. 2017, 578, 90-99. [CrossRef] [PubMed]

12. Zörb, C.; Geilfus, C.-M.; Mühling, K.H.; Ludwig-Müller, J. The influence of salt stress on ABA and auxin concentrations in two maize cultivars differing in salt resistance. J. Plant Physiol. 2013, 170, 220-224. [CrossRef] [PubMed]

13. Wani, K.I.; Naeem, M.; Castroverde, C.D.M.; Kalaji, H.M.; Albaqami, M.; Aftab, T. Molecular Mechanisms of Nitric Oxide (NO) Signaling and Reactive Oxygen Species (ROS) Homeostasis during Abiotic Stresses in Plants. Int. J. Mol. Sci. 2021, $22,9656$. [CrossRef] [PubMed]

14. Naing, A.H.; Kim, C.K. Abiotic stress-induced anthocyanins in plants: Their role in tolerance to abiotic stresses. Physiol. Plant. 2021, 172, 1711-1723. [CrossRef]

15. Ding, Y.; Jia, Y.; Shi, Y. OST1-mediated BTF3L phosphorylation positively regulates CBFs during plant cold responses. EMBO J. 2018, 37, e98228. [CrossRef]

16. Dong, C.; Xi, Y.; Chen, X.; Cheng, Z.-M. Genome-wide identification of AP2/EREBP in Fragaria vesca and expression pattern analysis of the FvDREB subfamily under drought stress. BMC Plant Biol. 2021, 21, 295. [CrossRef]

17. Zhao, Q.; Xiang, X.; Liu, D.; Yang, A.; Wang, Y. Tobacco Transcription Factor NtbHLH123 Confers Tolerance to Cold Stress by Regulating the NtCBF Pathway and Reactive Oxygen Species Homeostasis. Front. Plant Sci. 2018, 9, 381. [CrossRef]

18. Wan, F.-X.; Gao, J.; Wang, G.-L.; Niu, Y.; Wang, L.-Z.; Zhang, X.-G.; Wang, Y.-Q.; Pan, Y. Genome-wide identification of NAC transcription factor family and expression analysis of ATAF subfamily members under abiotic stress in eggplant. Sci. Hortic. 2021, 289, 110424. [CrossRef] 
19. Li, J.; Li, X.; Han, P.; Liu, H.; Gong, J.; Zhou, W.; Shi, B.; Liu, A.; Xu, L. Genome-wide investigation of bHLH genes and expression analysis under different biotic and abiotic stresses in Helianthus annuus L. Int. J. Biol. Macromol. 2021, 189, 72-83. [CrossRef]

20. Chini, A.; Boter, M.; Solano, R. Plant oxylipins: COI1/JAZs /MYC2 as the core jasmonic acid-signalling module. FEBS J. 2009, 276, 4682-4692. [CrossRef]

21. Staswick, P.E. JAZing up jasmonate signaling. Trends Plant Sci. 2008, 13, 66-71. [CrossRef] [PubMed]

22. Thines, B.; Katsir, L.; Melotto, M.; Niu, Y.; Mandaokar, A.D.; Liu, G.; Nomura, K.; He, S.Y.; Howe, G.A.; Browse, J. JAZ repressor proteins are targets of the SCFCOI1 complex during jasmonate signalling. Nature 2007, 448, 661-665. [CrossRef] [PubMed]

23. Srivastava, A.K.; Dutta, S.; Chattopadhyay, S. MYC2 regulates ARR16, a component of cytokinin signaling pathways, in Arabidopsis seedling development. Plant Direct 2019, 3, e00177. [CrossRef] [PubMed]

24. Verma, D.; Bhagat, P.K.; Sinha, A.K. MKK3-MPK6-MYC2 module positively regulates ABA biosynthesis and signalling in Arabidopsis. J. Plant Biochem. Biotechnol. 2020, 29, 785-795. [CrossRef]

25. Chen, D.; Shi, X.; Wang, W.; Wang, F.; Zhang, H. The Brassica napus MYC2 regulates drought tolerance by monitoring stomatal closure. Eur. J. Hortic. Sci. 2020, 85, 226-231. [CrossRef]

26. Yastreb, T.; Kolupaev, Y.E.; Havva, E.N.; Horielova, E.I.; Dmitriev, A.P. Involvement of the JIN1/MYC2 Transcription Factor in Inducing Salt Resistance in Arabidopsis Plants by Exogenous Hydrogen Sulfide. Cytol. Genet. 2020, 54, 96-102. [CrossRef]

27. Schmoyer, T.E. Apparatus and Method for Removing and Retarding Paraffin Buildup on Surfaces in Contact with Crude Oil and Natural Gas. U.S. Patent 2019/0152781A1, 23 May 2019.

28. Feng, X.-M.; Zhao, Q.; Zhao, L.-L.; Qiao, Y.; Xie, X.-B.; Li, H.-F.; Yao, Y.-X.; You, C.-X.; Hao, Y.-J. The cold-induced basic helix-loop-helix transcription factor gene MdCIbHLH1encodes an ICE-like protein in apple. BMC Plant Biol. 2012, 12, 22. [CrossRef]

29. Goujon, M.; McWilliam, H.; Li, W.; Valentin, F.; Squizzato, S.; Paern, J.; López, R. A new bioinformatics analysis tools framework at EMBL-EBI. Nucleic Acids Res. 2010, 38, W695-W699. [CrossRef]

30. Atchley, W.R.; Terhalle, W.; Dress, A. Positional Dependence, Cliques, and Predictive Motifs in the bHLH Protein Domain. J. Mol. Evol. 1999, 48, 501-516. [CrossRef]

31. Li, X.; Duan, X.; Jiang, H.; Sun, Y.; Tang, Y.; Yuan, Z.; Guo, J.; Liang, W.; Chen, L.; Yin, J.; et al. Genome-Wide Analysis of Basic/Helix-Loop-Helix Transcription Factor Family in Rice and Arabidopsis. Plant Physiol. 2006, 141, 1167-1184. [CrossRef]

32. Nesi, N.; Debeaujon, I.; Jond, C.; Pelletier, G.; Caboche, M.; Lepiniec, L. The TT8 Gene Encodes a Basic Helix-Loop-Helix Domain Protein Required for Expression of DFR and BAN Genes in Arabidopsis Siliques. Plant Cell 2000, 12, 1863-1878. [CrossRef] [PubMed]

33. Polichuk, D.R.; Zhang, Y.; Reed, D.; Schmidt, J.F.; Covello, P.S. A glandular trichome-specific monoterpene alcohol dehydrogenase from Artemisia annua. Phytochemistry 2010, 71, 1264-1269. [CrossRef] [PubMed]

34. Anfang, M.; Shani, E. Transport mechanisms of plant hormones. Curr. Opin. Plant Biol. 2021, 63, 102055. [CrossRef] [PubMed]

35. Pires, N.; Dolan, L. Origin and Diversification of Basic-Helix-Loop-Helix Proteins in Plants. Mol. Biol. Evol. 2010, $27,862-874$. [CrossRef] [PubMed]

36. Fu, J.; Liu, L.; Liu, Q.; Shen, Q.; Wang, C.; Yang, P.; Zhu, C.; Wang, Q. ZmMYC2 exhibits diverse functions and enhances JA signaling in transgenic Arabidopsis. Plant Cell Rep. 2019, 39, 273-288. [CrossRef]

37. Aleman, F.; Yazaki, J.; Lee, M.; Takahashi, Y.; Kim, A.Y.; Li, Z.; Kinoshita, T.; Ecker, J.; Schroeder, J.I. An ABA-increased interaction of the PYL6 ABA receptor with MYC2 Transcription Factor: A putative link of ABA and JA signaling. Sci. Rep. 2016, 6, 28941. [CrossRef]

38. Kemal, K.; John, M.M. MYC2: The Master in Action. Mol. Plant 2013, 6, 686-703.

39. Fu, J.; Xiao, Y.; Wang, Y.-F.; Liu, Z.-H.; Yang, K. Saline-alkaline stress in growing maize seedlings is alleviated by Trichoderma asperellum through regulation of the soil environment. Sci. Rep. 2021, 11, 11152. [CrossRef]

40. Xu, X.; Zhang, J.; Yan, B.; Wei, Y.; Ge, S.; Li, J.; Han, Y.; Li, Z.; Zhao, C.; Xu, J. The Adjustment of Membrane Lipid Metabolism Pathways in Maize Roots Under Saline-Alkaline Stress. Front. Plant Sci. 2021, 12, 635327. [CrossRef]

41. Verma, D.; Jalmi, S.; Bhagat, P.K.; Verma, N.; Sinha, A.K. A bHLH transcription factor, MYC2, imparts salt intolerance by regulating proline biosynthesis in Arabidopsis. FEBS J. 2019, 287, 2560-2576. [CrossRef]

42. Todaka, D.; Shinozaki, K.; Yamaguchi-Shinozaki, K. Recent advances in the dissection of drought-stress regulatory networks and strategies for development of drought-tolerant transgenic rice plants. Front. Plant 2015, 6, 84. [CrossRef] [PubMed]

43. Jeong, J.S.; Kim, Y.S.; Redillas, M.C.F.R.; Jang, G.; Jung, H.; Bang, S.W.; Choi, Y.D.; Ha, S.-H.; Reuzeau, C.; Kim, J.-K. OsNAC5overexpression enlarges root diameter in rice plants leading to enhanced drought tolerance and increased grain yield in the field. Plant Biotechnol. J. 2012, 11, 101-114. [CrossRef] [PubMed]

44. Ritonga, F.N.; Ngatia, J.N.; Wang, Y.; Khoso, M.A.; Farooq, U.; Chen, S. AP2/ERF, an important cold stress-related transcription factor family in plants: A review. Physiol. Mol. Biol. Plants 2021, 27, 1953-1968. [CrossRef] [PubMed]

45. He, H.; Lei, Y.; Yi, Z.; Raza, A.; Zeng, L.; Yan, L.; Xiaoyu, D.; Yong, C.; Xiling, Z. Study on the mechanism of exogenous serotonin improving cold tolerance of rapeseed (Brassica napus L.) seedlings. Plant Growth Regul. 2021, 94, 161-170. [CrossRef]

46. Xiong, H.; Yu, J.; Miao, J.; Li, J.; Zhang, H.; Wang, X.; Liu, P.; Zhao, Y.; Jiang, C.; Yin, Z.; et al. Natural Variation in OsLG3 Increases Drought Tolerance in Rice by Inducing ROS Scavenging. Plant Physiol. 2018, 178, 451-467. [CrossRef] 
47. Jiang, D.; Lu, B.; Liu, L.; Duan, W.; Meng, Y.; Li, J.; Zhang, K.; Sun, H.; Zhang, Y.; Dong, H.; et al. Exogenous melatonin improves the salt tolerance of cotton by removing active oxygen and protecting photosynthetic organs. BMC Plant Biol. 2021, $21,331$. [CrossRef]

48. Hu, H.; Liu, H.; Du, G.; Fei, Y.; Deng, G.; Yang, Y.; Feihu, L. Fiber and seed type of hemp (Cannabis sativa L.) responded differently to salt-alkali stress in seedling growth and physiological indices. Ind. Crop. Prod. 2019, 129, 624-630. [CrossRef]

49. Yue, X.; Zhang, G.; Zhao, Z.; Yue, J.; Pu, X.; Sui, M.; Zhan, Y.; Shi, Y.; Wang, Z.; Meng, G.; et al. A Cryophyte Transcription Factor, CbABF1, Confers Freezing, and Drought Tolerance in Tobacco. Front. Plant Sci. 2019, 10, 699. [CrossRef]

50. Zhang, L.; Guo, X.; Zhang, Z.; Wang, A.; Zhu, J. Cold-regulated gene LeCOR413PM2 confers cold stress tolerance in tomato plants. Gene 2021, 764, 145097. [CrossRef]

51. Gangwar, R.; Kumari, P.; Chatrath, A.; Prasad, R. Characterisation of recombinant thermostable manganese-superoxide dismutase (NeMnSOD) from Nerium oleander. Mol. Biol. Rep. 2020, 47, 3251-3270. [CrossRef]

52. Lin, K.-H.; Sei, S.-C.; Su, Y.-H.; Chiang, C.-M. Overexpression of the Arabidopsis and winter squash superoxide dismutase genes enhances chilling tolerance via ABA-sensitive transcriptional regulation in transgenic Arabidopsis. Plant Signal. Behav. 2019, 14, 1685728. [CrossRef] [PubMed]

53. Tounsi, S.; Feki, K.; Kamoun, Y.; Saïdi, M.N.; Jemli, S.; Ghorbel, M.; Alcon, C.; Brini, F. Highlight on the expression and the function of a novel MnSOD from diploid wheat (T. monococcum) in response to abiotic stress and heavy metal toxicity. Plant Physiol. Biochem. 2019, 142, 384-394. [CrossRef] [PubMed]

54. Divya, K.; Palakolanu, S.R.; Kishor, P.K.; Rajesh, A.S.; Vadez, V.; Sharma, K.K.; Mathur, P.B. Functional characterization of late embryogenesis abundant genes and promoters in pearl millet (Pennisetum glaucum L.) for abiotic stress tolerance. Physiol. Plant. 2021, 173, 1616-1628. [CrossRef] [PubMed] 